OPEN ACCESS

Edited by:

Kenjiro Ono

Showa University, Japan

Reviewed by:

Vasileios-Arsenios Lioutas, Harvard Medical School,

United States

Hayato Tada,

Kanazawa University, Japan

*Correspondence:

Chuansheng Zhao

cszhao@mail.cmu.edu.cn

Mei Zhao

zhaom1@sj-hospital.org

Received: 07 October 2019 Accepted: 09 January 2020 Published: 30 January 2020

Citation:

Zhou Z, Liang Y, Zhang $X, X U$ J, Lin J, Zhang $R$, Kang $K$, Liu C, Zhao $C$ and Zhao M (2020) Low-Density Lipoprotein Cholesterol and Alzheimer's Disease: A Systematic Review and Meta-Analysis. Front. Aging Neurosci. 12:5. doi: 10.3389/fnagi.2020.00005

\section{Low-Density Lipoprotein Cholesterol and Alzheimer's Disease: A Systematic Review and Meta-Analysis}

\author{
Zhike Zhou ${ }^{1}$, Yifan Liang ${ }^{2}$, Xiaoqian Zhang ${ }^{2}$, Junjie X ${ }^{3}$, Jueying Lin ${ }^{4}$, Rongwei Zhang ${ }^{1}$, \\ Kexin Kang ${ }^{1}$, Chang Liu ${ }^{2}$, Chuansheng Zhao ${ }^{2 *}$ and Mei Zhao ${ }^{5 *}$ \\ 'Department of Geriatrics, The First Affiliated Hospital, China Medical University, Shenyang, China, ${ }^{2}$ Department of \\ Neurology, The First Affiliated Hospital, China Medical University, Shenyang, China, ${ }^{3}$ Department of Laboratory Medicine, \\ The First Affiliated Hospital, China Medical University, Shenyang, China, ${ }^{4}$ Department of Emergency, Zhongshan Hospital \\ Xiamen University, Xiamen, China, ${ }^{5}$ Department of Cardiology, The Shengjing Affiliated Hospital, China Medical University, \\ Shenyang, China
}

Objective: To assess the association between low-density lipoprotein cholesterol (LDL-C) and risk of Alzheimer's disease (AD).

Methods: Embase, Pubmed, and Web of Science were searched until June 2019. Standard mean difference (SMD) with 95\% confidence intervals (Cl) was estimated using random-effects models.

Results: Our meta-analysis of 26 studies revealed higher levels of LDL-C in AD than that of non-dementia controls $(S M D=0.35,95 \% \mathrm{Cl} 0.12-0.58, p<0.01)$. The meta-regression analysis on confounders showed that age $(p<0.01$, Adj $R$-squared $=92.41 \%$ ) and cardiovascular disease $(p=0.01$, Adj $R$-squared $=85.21 \%)$, but not the body mass index, education, smoking, hypertension and diabetes mellitus, exerted an impact on the relationship between LDL-C and risk of $\mathrm{ICH}$. Further subgroup analysis of age showed LDL-c levels in AD patients aged 60-70 were higher than that of non-dementia ( $60 \leq$ age $<70$ : SMD $=0.80$, 95\% Cl 0.23-1.37, $p<0.01$ ); but no association between the SMD of AD in LDL-C and age over 70 was noted across the studies $(70 \leq$ age $<77$ : SMD $=-0.02,95 \% \mathrm{Cl}-0.39 \sim 0.34, p=9.0 ; 77 \leq$ age < 80: $\mathrm{SMD}=0.15,95 \% \mathrm{Cl}-0.17 \sim 0.47, p=0.35 ; \geq 80: \mathrm{SMD}=0.53,95 \% \mathrm{Cl}$ $-0.04 \sim 1.11, p=0.07)$. The concentrations of LDL-c during the quintile interval of $3 \sim 4$ were positively associated with $\mathrm{AD}(121 \leq$ concentration $<137: \mathrm{SMD}=0.98,95 \% \mathrm{Cl}$ $0.13 \sim 1.82, p=0.02 ; \geq 137: \mathrm{SMD}=0.62,95 \% \mathrm{Cl} 0.18 \sim 1.06, p<0.01)$; whereas there was no correlation between AD and LDL-c within the quintile interval of $1 \sim 2$ (103.9 $\leq$ concentration < 112: $\mathrm{SMD}=0.08,95 \% \mathrm{Cl}-0.20 \sim 0.35, p=0.59 ; 112 \leq$ concentration $<121: \mathrm{SMD}=-0.26,95 \% \mathrm{Cl}-0.58 \sim 0.06, p=0.11)$.

Conclusions: Elevated concentration of LDL-c (>121 mg/dl) may be a potential risk factor for $A D$. This association is strong in patients aged 60-70 years, but vanishes with advancing age.

Keywords: LDL-c, Alzheimer's disease, risk factor, meta-analysis, association 


\section{INTRODUCTION}

Alzheimer's disease (AD) is a neurodegenerative disorder characterized by progressive and irreversible decline in cognition (Kapogiannis et al., 2019). It accounts for approximate twothirds of all dementias with an increasing morbidity (Prince et al., 2013) and heavy burden of finance (Reitz and Mayeux, 2014). Recognizing that disease-modifying interventions have the greatest chance of success, the emphasis has shifted to controlling underlying risk factors such as diabetes mellitus (Martinez-Valbuena et al., 2019), hypertension (Barnes and Yaffe, 2011), smoking (Durazzo et al., 2014), sleep disturbances (Sindi et al., 2018), and low educational attainment (Barnes and Yaffe, 2011). Moreover, it is reported that APOE4 affects the pathology of $\mathrm{AD}$ by multifaceted mechanisms, including abnormal lipid metabolism, inflammatory alterations, and impairment of astrocyte- and microglia-mediated $A \beta$ clearance (Lin et al., 2018; Jeong et al., 2019). Dyslipidemia mainly high level of low-density lipoprotein cholesterol (LDL-c) is thought to have vascular and neurotoxic effects and is implicated in the pathogenesis of $\mathrm{AD}$ (Whitmer et al., 2005).

LDL-c, which is synthesized in the blood vessels and degraded in the liver, is a type of lipoprotein particle that carries cholesterol into cells of peripheral tissue. LDL-c causes atherosclerotic cardiovascular disease (Ference et al., 2017), and lowering LDL-c level has been demonstrated to reduce myocardial infarction and stroke in high-risk populations (Schaefer, 2014; Sabatine et al., 2015). However, whether elevated LDL-c level is related to the risk of $\mathrm{AD}$ remains unconfirmed. Several studies reported that patients with AD exhibited higher level of LDL-c when compared with normal controls (Lesser et al., 2009; Wingo et al., 2019). In contrast, some of the studies detected no significant difference in LDL-c level between $\mathrm{AD}$ patients and healthy controls (Davidson et al., 2012; Li et al., 2017). The patients included in the above studies did not exclude the use of cholesterollowering drugs, which played vague role in pathogenesis of $\mathrm{AD}$ and might not represent the true LDL-c level of $\mathrm{AD}$ patients. Given these uncertainties and contradictions, it prompted us to conduct a meta-analysis of existing studies without the interference of cholesterol-lowering drugs to elucidate a more precise association between LDL-c and AD than individual studies, with the expectation of an aggregate estimate of $\mathrm{AD}$ risk for specified changes in serum LDL-c.

\section{MATERIALS AND METHODS}

\section{Inclusion and Exclusion Criteria}

Studies were included if they met the criteria as follows: (1) the diagnosis of $\mathrm{AD}$ is based on the validated diagnostic criteria. Specifically, the Diagnostic and Statistical Manual of Mental Disorders (DSM) -III, -IV, or -V criteria (American Psychiatric Association, 1980, 1987, 1994, 2013), International Classification of Diseases (ICD)-10 criteria, and the National Institute of Neurological and Communicative Disorders and Stroke/Alzheimer's Disease and Related Disorders Association (NINCDS-ADRDA) (McKhann et al., 1984) criteria were used for the diagnosis of $\mathrm{AD}$. Six papers that used other diagnostic criteria but were substantially consistent with those we specified were also included (Caramelli et al., 1999; Lesser et al., 2001; Solfrizzi et al., 2002; Macesic et al., 2017; Chen et al., 2019); (2) a measure of association was described for serum LDL-c to incident $\mathrm{AD}$; (2) the mean levels of LDL-c in AD and non-dementia were recorded; (3) study design was case-control study; (4) the report with large sample was used if subjects came from one center. The exclusion criteria were: (1) duplicated publications (2) studies with overlapping data; (3) studies recorded participants receiving statins or other cholesterol-lowering drugs; (4) the complications of severe liver dysfunctions, heart failure and malignant diseases; (5) case reports, animal studies, letters to editor, reviews, and comments.

\section{Literature Search}

We sought available studies on the relationship between serum LDL-c and Alzheimer's disease using a retrieval of pubmed (until June 2019), Embase (until June 2019) and Web of Science (1950 to June 2019) databases. Search terms used for the studies were "Alzheimer," "dementia," "cognitive," "amentia," and "low density lipoprotein." Reference lists of involved reviews were also checked for additional articles in the original literature search, limited to English language studies on human subjects.

\section{Data Extraction and Collation}

Two investigators independently abstracted all search data and any discrepancies were resolved by group discussion. The general characteristics of included studies were as follows: first author, publication year, country, detection method, male subjects, age, and LDL-c levels (Table 1). Other baseline characteristics included body mass index, education, and vascular risk factors such as smoking, hypertension, diabetes mellitus and cardiovascular disease (CVD), as shown in Supplementary Table 2. The pooled data on baseline characteristics of included studies were extracted and summarized (Table 2). The developed guidelines of preferred reporting items for systematic reviews and meta-analyses (PRISMA) (protocol number: PROSPERO CRD42019127818) were listed (Supplementary Table 1) (Moher et al., 2009).

\section{Statistical Analysis}

Data analyses were conducted by using the software STATA version 15.0 and Review Manager 5.3. Effect size of standard mean difference (SMD) for continuous variables, or odds ratio (OR) for binary variables, with $95 \%$ confidence intervals (CI) were calculated to compare the differences in LDL-c level between $\mathrm{AD}$ and non-dementia group. The pooled SMD was assessed by the $Z$-test and the inter-study heterogeneity was estimated by the $\mathrm{I}^{2}$ test $(25,50$, and $75 \%$ representing low, moderate, and high degrees of heterogeneity, respectively; Higgins et al., 2003). Fixed effects models were applied for the evidence of statistical heterogeneity $\left(I^{2}<50 \%\right.$, and $\left.p \geq 0.05\right)$; otherwise, random effects models were adopted (Higgins and Thompson, 2002; Higgins et al., 2003). To further assess the sources of heterogeneity, meta-regression analyses were utilized to evaluate the effects of confounding factors on the association between LDL-c levels and AD. A key factor considered was 
TABLE 1 | General characteristics of the included studies.

\begin{tabular}{|c|c|c|c|c|c|c|c|c|}
\hline \multirow[b]{2}{*}{ References } & \multirow[b]{2}{*}{ Country } & \multirow[b]{2}{*}{ Detecting methods } & \multicolumn{3}{|c|}{ Alzheimer's disease } & \multicolumn{3}{|c|}{ Controls } \\
\hline & & & Male/n & LDL-c, mg/dl & Age, Years & Male/n & LDL-c, mg/dl & Age, Years \\
\hline Ban et al. (2009) & Japan & Precipitation & 79/197 & $123 \pm 2$ & $80 \pm 1$ & $29 / 47$ & $121 \pm 4$ & $75 \pm 1$ \\
\hline Cacabelos et al. (2003) & Spain & NR & $\mathrm{NR} / 147$ & $155.69 \pm 39.72$ & $71.73 \pm 9.61$ & NR/109 & $155.22 \pm 43.5$ & $50.20 \pm 12.06$ \\
\hline Caramelli et al. (1999) & Brazil & NR & 24-Nov & $131.23 \pm 35.53$ & $67.2 \pm 10.6$ & $13 / 32$ & $126.47 \pm 31.07$ & $68.2 \pm 10.6$ \\
\hline Chen et al. (2019) & China & Enzymatic & $56 / 117$ & $130.67 \pm 34.73$ & $67.64 \pm 6.65$ & $44 / 117$ & $95.25 \pm 23.46$ & $66.06 \pm 6.00$ \\
\hline Hoshino et al. (2002) & Japan & Precipitation & $23 / 82$ & $119.1 \pm 27.7$ & $77.0 \pm 6.8$ & $13 / 40$ & $110 \pm 24.4$ & $84.2 \pm 3.1$ \\
\hline Kouzuki et al. (2018) & Japan & NR & $16 / 42$ & $110.8 \pm 39.4$ & $80.5 \pm 5.7$ & $5 / 18$ & $119.2 \pm 35.7$ & $75.6 \pm 5.5$ \\
\hline Kuo et al. (1998) & America & Chromatography & NR/64 & $124 \pm 7$ & $81.6 \pm 0.9$ & NR/36 & $95.5 \pm 5$ & $78.7 \pm 1.3$ \\
\hline Lehtonen and Luutonen (1986) & Finland & Precipitation & $0 / 22$ & $138.46 \pm 51.92$ & $\geq 90$ & $0 / 23$ & $114.23 \pm 28.85$ & $\geq 90$ \\
\hline Lesser et al. (2001) & America & Precipitation & $N R / 44$ & $132.5 \pm 40.5$ & $87.0 \pm 8.5$ & $\mathrm{NR} / 22$ & $119.5 \pm 38$ & $82.0 \pm 7$ \\
\hline Macesic et al. (2017) & Serbia & Friedewald & $18 / 62$ & $165.38 \pm 38.46$ & $73.1 \pm 5.8$ & $20 / 40$ & $126.92 \pm 30.77$ & $68.4 \pm 5.5$ \\
\hline Mamo et al. (2008) & Australia & Centrifugation & $\mathrm{NR} / 10$ & $117.31 \pm 10.77$ & $79.2 \pm 1.8$ & $N R / 10$ & $118.85 \pm 7.69$ & $80.5 \pm 1.5$ \\
\hline Moroney et al. (1999) & America & Friedewald & $63 / 225$ & $111.54 \pm 33.46$ & $77.7 \pm 6.3$ & $248 / 764$ & $120 \pm 34.23$ & $74.1 \pm 5.5$ \\
\hline Panza et al. (2003) & Italy & Friedewald & $15 / 49$ & $119.23 \pm 34.62$ & $71.6 \pm 9.3$ & $13 / 45$ & $142.31 \pm 38.46$ & $65.8 \pm 11.6$ \\
\hline Paragh et al. (2002) & Hungary & Friedewald & $10 / 30$ & $147.69 \pm 23.08$ & $64.3 \pm 11.7$ & $14 / 40$ & $100 \pm 23.08$ & $72.3 \pm 9.6$ \\
\hline Reitz et al. (2004) & America & Friedewald & $55 / 244$ & $120.11 \pm 35.8$ & $82.85 \pm 7.3$ & $760 / 2226$ & $120.16 \pm 34.3$ & $76.42 \pm 6.3$ \\
\hline Ryglewicz et al. (2002) & Poland & Enzymatic & NR/26 & $149 \pm 38$ & $67 \pm 8.4$ & $N R / 46$ & $138 \pm 38.2$ & $67.5 \pm 6.9$ \\
\hline Scacchi et al. (1998) & Italy & Friedewald & $23 / 80$ & $113.08 \pm 38.08$ & $83.5 \pm 5.9$ & $36 / 155$ & $132.69 \pm 45.38$ & $78.3 \pm 7.0$ \\
\hline Shafagoj et al. (2018) & Jordan & Enzymatic & $14 / 38$ & $103.9 \pm 32.7$ & $74.2 \pm 5.4$ & $11 / 33$ & $113.6 \pm 26.4$ & $72.4 \pm 6.3$ \\
\hline Solfrizzi et al. (2002) & Italy & Friedewald & $12 / 49$ & $117.31 \pm 32.69$ & $71.6 \pm 9.3$ & $13 / 45$ & $141.92 \pm 37.69$ & $65.8 \pm 11.6$ \\
\hline Tang et al. (2019) & China & Chromatography & $78 / 143$ & $109.95 \pm 25.11$ & $62.89 \pm 8.38$ & $75 / 140$ & $100.63 \pm 23$ & $64.10 \pm 9.49$ \\
\hline Warren et al. (2012) & America & NR & $45 / 150$ & $106.8 \pm 36.5$ & $79.5 \pm 6.17$ & $61 / 197$ & $88.3 \pm 37.17$ & $70 \pm 6.33$ \\
\hline Watanabe et al. (2005) & Japan & Friedewald & $\mathrm{NR} / 106$ & $106 \pm 34$ & $79 \pm 7$ & NR/227 & $100 \pm 37$ & $76 \pm 10$ \\
\hline Wolf et al. (2004) & Sweden & Enzymatic & $9 / 25$ & $153.85 \pm 38.46$ & $77.9 \pm 3.0$ & $8 / 26$ & $146.15 \pm 38.46$ & $78.5 \pm 3.0$ \\
\hline Yamamoto et al. (2005) & Japan & Friedewald & $24 / 61$ & $108 \pm 36$ & $80 \pm 6$ & $17 / 32$ & $105 \pm 38$ & $77 \pm 5$ \\
\hline Yavuz et al. (2008) & Turkey & Enzymatic & 49/132 & $125 \pm 37.43$ & $74.1 \pm 7.4$ & $52 / 158$ & $125.6 \pm 34.43$ & $74.5 \pm 6.3$ \\
\hline Wehr et al. (2006) & Poland & Enzymatic & $33 / 97$ & $141.5 \pm 40.7$ & $71.8 \pm 7.9$ & $65 / 139$ & $125.6 \pm 46.6$ & $70.5 \pm 8.8$ \\
\hline
\end{tabular}

n, number; LDL-c, low-density lipoprotein cholesterol; NR, not reported.

the adjustment for age, given its modifying effect on LDL-c for the incidence of $\mathrm{AD}$. Subgroup analysis based on age (quartile: $60 \leq$ age $<70,70 \leq$ age $<77,77 \leq$ age $<80$, and $\geq 80$ ), concentration (quartile: $103.9 \leq$ concentration $<112,112 \leq$ concentration $<121,121 \leq$ concentration $<137$, and $\geq 137)$, and sample size ( $<50$ and more) in a series of studies were performed in LDL-c for the risk estimates of AD. Sensitivity analysis was carried out by removing any one of the studies each time to examine its impact on the pooled risk estimates. Publication bias was evaluated by Egger's weighted regression test, and $p<0.05$ indicated a possible risk of publication bias (Egger et al., 1997).

\section{RESULTS}

\section{Study Selection and Characteristics}

The preliminary retrieval generated 1,388 articles, which reduced to 124 by reviewing title and abstract. After inspection of the full text, 98 articles were further excluded. Subsequently, 26 eligible articles including a hand search of citations in the reports of published studies or reviews were selected into the meta-analysis (for detailed steps, see Figure 1; Lehtonen and Luutonen, 1986; Kuo et al., 1998; Scacchi et al., 1998;
TABLE 2 | Pooled weighted characteristics.

\begin{tabular}{lccc}
\hline & \multicolumn{2}{c}{ Alzheimer's disease vs. control arm } & \multirow{2}{*}{$\boldsymbol{p}$-Value } \\
\cline { 2 - 3 } & SMD & $\mathbf{9 5 \%} \mathbf{C l}$ & \\
\hline Age & 0.62 & $(0.28,0.95)$ & $<0.001$ \\
Body mass index & -0.31 & $(-0.48,-0.13)$ & 0.001 \\
Education & 0.26 & $(-0.78,1.30)$ & 0.626 \\
& Odds ratio & $\mathbf{9 5 \%} \mathbf{C l}$ & $\boldsymbol{p}$-Value \\
Male gender & 0.86 & $(0.71,1.04)$ & 0.112 \\
Smoking & 1.33 & $(0.71,2.47)$ & 0.376 \\
Hypertension & 0.91 & $(0.62,1.35)$ & 0.639 \\
Diabetes mellitus & 1.02 & $(0.82,1.26)$ & 0.884 \\
Cardiovascular disease & 1.28 & $(0.61,2.70)$ & 0.513 \\
\hline
\end{tabular}

SMD, standard mean difference; $\mathrm{Cl}$, confidence interval.

Caramelli et al., 1999; Moroney et al., 1999; Lesser et al., 2001; Hoshino et al., 2002; Paragh et al., 2002; Ryglewicz et al., 2002; Solfrizzi et al., 2002; Cacabelos et al., 2003; Panza et al., 2003; Reitz et al., 2004; Wolf et al., 2004; Watanabe et al., 2005; Yamamoto et al., 2005; Wehr et al., 2006; Mamo 
et al., 2008; Yavuz et al., 2008; Ban et al., 2009; Warren et al., 2012; Macesic et al., 2017; Kouzuki et al., 2018; Shafagoj et al., 2018; Chen et al., 2019; Tang et al., 2019). Table 1 showed general characteristics of twenty-six studies involving 2,266 AD patients and 4,767 non-dementia controls. Table 2 gives details of included studies that provided pooled data on baseline characteristics between $\mathrm{AD}$ patients and non-dementia controls. Figure 2 revealed the standard mean difference of $\mathrm{AD}$ in serum LDL-c in each study and the summary SMD for all studies combined. Table 3 showed the association between LDL-c and AD according to category of age (quartile interval), LDL-c concentration (quartile interval), and sample

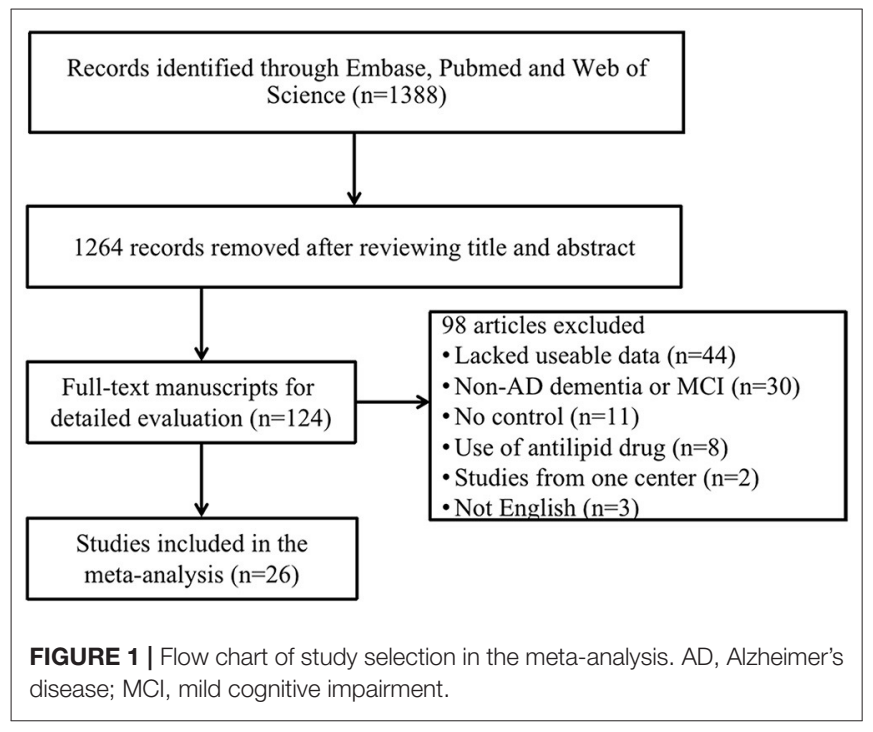

size ( $n<50$ and more). Meta-regression analyses of age, body mass index (BMI), education, smoking, hypertension, diabetes mellitus (Figure 3) and CVD (Supplementary Figure 1) were conducted to assess the effects of these confounding factors on the association of LDL-c levels with AD. Stroke data from $\mathrm{AD}$ patients and non-dementia controls were insufficient for meta-regression analysis.

\section{Meta-Analysis}

Random effects models were prespecified to combine estimates from different studies based on existence of high heterogeneity $\left(I^{2}=92.8 \%, p<0.01\right)$. Results from the meta-analysis of 26 studies revealed higher levels of LDL-c in $\mathrm{AD}$ than that of non-dementia controls (SMD $=0.35,95 \%$ CI $0.12 \sim 0.58$, $p<0.01$; Figure 2), which was consistent with the results of the fixed-effect model (SMD $=0.16,95 \%$ CI 0.10 0.22, $p<0.01$; Supplementary Figure 2). The meta-regression of confounding factors showed that age $(p<0.01$, Adj $R$-squared $=92.41 \%$; Figure 3A) and CVD $(p=0.01$, Adj $R$-squared $=85.21 \%$; Supplementary Figure 1) exerted an effect on the association of LDL-c with $\mathrm{AD}$; whereas other parameters including $\mathrm{BMI}$ ( $p=0.063$, Adj $R$-squared $=-6.53 \%$; Figure 3B), education $(p=0.50$, Adj $R$-squared $=-11.58 \%$; Figure $3 \mathrm{C})$, smoking $(p=0.10$, Adj $R$-squared $=43.90 \%$; Figure 3D), hypertension $(p=0.98$, Adj $R$-squared $=-22.11 \%$; Figure $3 E)$ and diabetes mellitus ( $p=0.57$, Adj $R$-squared $=-13.04 \%$; Figure $3 F$ ) had no impact on the outcomes. As shown in Table 2, we found no statistic differences of the pooled weighted characteristics on male gender $(\mathrm{OR}=0.86,95 \% \mathrm{CI} 0.71 \sim 1.04, p=0.11)$, education $(\mathrm{SMD}=0.26,95 \% \mathrm{CI}-0.78 \sim 1.30, p<0.63)$, smoking $(\mathrm{OR}=$ $1.33,95 \%$ CI $0.71 \sim 2.47, p=0.38)$, hypertension $(\mathrm{OR}=0.91,95 \%$ CI $0.62 \sim 1.35, p=0.64$ ), diabetes mellitus (OR $=1.02,95 \% \mathrm{CI}$

\begin{tabular}{|c|c|c|c|c|c|c|c|c|c|c|}
\hline \multirow[b]{2}{*}{ Study or Subgroup } & \multicolumn{3}{|c|}{ Alzheimer's disease } & \multicolumn{3}{|c|}{ Non-dementia } & \multicolumn{2}{|c|}{ Std. Mean Difference } & \multirow{2}{*}{\multicolumn{2}{|c|}{$\begin{array}{l}\text { Std. Mean Difference } \\
\text { IV, Random, } 95 \% \mathrm{Cl}\end{array}$}} \\
\hline & Mean & SD & Total & Mean & SD & Total & Weight & IV, Random, $95 \% \mathrm{Cl}$ & & \\
\hline Ban Y 2009 & 123 & 2 & 197 & 121 & 4 & 47 & $4.1 \%$ & $0.80[0.47,1.12]$ & & - \\
\hline Cacabelos R 2003 & 155.69 & 39.72 & 147 & 155.22 & 43.5 & 109 & $4.2 \%$ & $0.01[-0.24,0.26]$ & & \\
\hline Caramelli P 1999 & 131.23 & 35.53 & 24 & 126.47 & 31.07 & 32 & $3.6 \%$ & $0.14[-0.39,0.67]$ & & - \\
\hline Chen H 2019 & 130.67 & 34.73 & 117 & 95.25 & 23.46 & 117 & $4.2 \%$ & $1.19[0.91,1.47]$ & & $\sim$ \\
\hline Hoshino T 2002 & 119.1 & 27.7 & 82 & 110 & 24.4 & 40 & $3.9 \%$ & $0.34[-0.04,0.72]$ & & 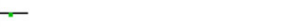 \\
\hline Kouzuki M 2018 & 110.8 & 39.4 & 42 & 119.2 & 35.7 & 18 & $3.5 \%$ & $-0.22[-0.77,0.34]$ & & - \\
\hline Kuo YM 1998 & 124 & 7 & 64 & 95.5 & 5 & 36 & $3.0 \%$ & $4.45[3.70,5.20]$ & & \\
\hline Lehtonen A 1986 & 138.46 & 51.92 & 22 & 114.23 & 28.85 & 23 & $3.4 \%$ & $0.57[-0.03,1.17]$ & & $\cdots$ \\
\hline Lesser G 2001 & 132.5 & 40.5 & 44 & 119.5 & 38 & 22 & $3.6 \%$ & $0.32[-0.19,0.84]$ & & - \\
\hline Macesic M 2017 & 165.38 & 38.46 & 62 & 126.92 & 30.77 & 40 & $3.8 \%$ & $1.07[0.65,1.50]$ & & 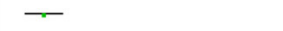 \\
\hline Mamo JC 2008 & 117.31 & 10.77 & 10 & 118.85 & 7.69 & 10 & $2.7 \%$ & $-0.16[-1.04,0.72]$ & - & - \\
\hline Moroney JT 1999 & 111.54 & 33.46 & 225 & 120 & 34.23 & 764 & $4.3 \%$ & $-0.25[-0.40,-0.10]$ & - & \\
\hline Panza F 2003 & 119.23 & 34.62 & 49 & 142.31 & 38.46 & 45 & $3.9 \%$ & $-0.63[-1.04,-0.21]$ & 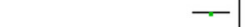 & \\
\hline Paragh G 2002 & 147.69 & 23.08 & 30 & 100 & 23.08 & 40 & $3.4 \%$ & $2.04[1.46,2.63]$ & & $\longrightarrow$ \\
\hline Reitz C 2004 & 120.11 & 35.8 & 244 & 120.16 & 34.3 & 2226 & $4.4 \%$ & $-0.00[-0.13,0.13]$ & & \\
\hline Ryglewicz D 2002 & 149 & 38 & 26 & 138 & 38.2 & 46 & $3.7 \%$ & $0.29[-0.20,0.77]$ & & \\
\hline Scacchi R 1998 & 113.08 & 38.08 & 80 & 132.69 & 45.38 & 155 & $4.2 \%$ & $-0.45[-0.73,-0.18]$ & - & \\
\hline Shafagoj YA 2018 & 103.9 & 32.7 & 38 & 113.6 & 26.4 & 33 & $3.7 \%$ & $-0.32[-0.79,0.15]$ & $\rightarrow$ & \\
\hline Solfrizzi V 2002 & 117.31 & 32.69 & 49 & 141.92 & 37.69 & 45 & $3.9 \%$ & $-0.69[-1.11,-0.28]$ & - & \\
\hline Tang Y 2019 & 109.95 & 25.11 & 143 & 100.63 & 23 & 140 & $4.2 \%$ & $0.39[0.15,0.62]$ & & - \\
\hline Warren MW 2012 & 106.8 & 36.5 & 150 & 88.3 & 37.17 & 197 & $4.3 \%$ & $0.50[0.28,0.72]$ & & - \\
\hline Watanabe T 2005 & 106 & 34 & 106 & 100 & 37 & 227 & $4.2 \%$ & $0.17[-0.06,0.40]$ & & - \\
\hline Werh H 2006 & 141.5 & 40.7 & 97 & 125.6 & 46.6 & 139 & $4.2 \%$ & $0.36[0.10,0.62]$ & & - \\
\hline Wolf H 2004 & 153.85 & 38.46 & 25 & 146.15 & 38.46 & 26 & $3.5 \%$ & $0.20[-0.35,0.75]$ & & - \\
\hline Yamamoto H 2005 & 108 & 36 & 61 & 105 & 38 & 32 & $3.8 \%$ & $0.08[-0.35,0.51]$ & & - \\
\hline Yavuz BB 2008 & 125 & 37.43 & 132 & 125.6 & 34.43 & 158 & $4.2 \%$ & $-0.02[-0.25,0.21]$ & 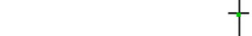 & - \\
\hline \multirow{2}{*}{\multicolumn{9}{|c|}{$\begin{array}{l}\text { Heterogeneity: } \text { Tau }^{2}=0.31 ; \mathrm{Chi}^{2}=362.62, \mathrm{df}=25(\mathrm{P}<0.00001) ; \mathrm{I}^{2}=93 \% \\
\text { Test for overall effect: } Z=2.99(P=0.003)\end{array}$}} & & \\
\hline & & & & & & & & & $\begin{array}{ccc}-4 & -2 & 0 \\
\text { Favours [Non-dementia] }\end{array}$ & $\begin{array}{cc}1 & 1 \\
\text { Favours [Alzheimer's disease] }\end{array}$ \\
\hline
\end{tabular}


TABLE 3 | Results of subgroup analysis on age, dose of LDL-c and sample size.

\begin{tabular}{|c|c|c|c|c|c|c|c|}
\hline \multirow[t]{2}{*}{ Analyte } & \multirow[t]{2}{*}{ Studies } & \multirow[t]{2}{*}{$n$ (cases/control) } & \multirow[t]{2}{*}{ Stratification } & \multirow[t]{2}{*}{ Interval } & \multicolumn{2}{|c|}{ AD vs. control arm } & \multirow[t]{2}{*}{$p$-value } \\
\hline & & & & & SMD & $95 \% \mathrm{Cl}$ & \\
\hline \multirow[t]{4}{*}{ Age (yrs) } & $\begin{array}{l}5 \text { (Caramelli et al., 1999; Paragh et al., 2002; Reitz et al., 2004; } \\
\text { Kouzuki et al., 2018; Chen et al., 2019) }\end{array}$ & $340 / 375$ & Quartile1 & $60-70$ & 0.80 & $(0.23,1.37)$ & $<0.01$ \\
\hline & $\begin{array}{l}7 \text { (Solfrizzi et al., 2002; Cacabelos et al., 2003; Panza et al., } \\
\text { 2003; Wehr et al., 2006; Yavuz et al., 2008; Macesic et al., } \\
\text { 2017; Shafagoj et al., 2018) }\end{array}$ & $574 / 569$ & Quartile2 & $70-77$ & -0.02 & $(-0.39,0.34)$ & 0.90 \\
\hline & $\begin{array}{l}6 \text { (Moroney et al., 1999; Hoshino et al., 2002; Wolf et al., 2004; } \\
\text { Watanabe et al., 2005; Mamo et al., 2008; Warren et al., 2012) }\end{array}$ & $598 / 1264$ & Quartile3 & $77-80$ & 0.15 & $(-0.17,0.47)$ & 0.35 \\
\hline & $\begin{array}{l}8 \text { (Lehtonen and Luutonen, 1986; Kuo et al., 1998; Scacchi } \\
\text { et al., 1998; Lesser et al., 2001; Reitz et al., 2004; Yamamoto } \\
\text { et al., 2005; Ban et al., 2009; Kouzuki et al., 2018) }\end{array}$ & $754 / 2559$ & Quartile4 & $\geq 80$ & 0.53 & $(-0.04,1.11)$ & 0.07 \\
\hline \multirow[t]{4}{*}{ Concentration (mg/dl) } & $\begin{array}{l}\text { 7(Moroney et al., 1999; Watanabe et al., 2005; Yamamoto et al., } \\
\text { 2005; Warren et al., 2012; Kouzuki et al., 2018; Shafagoj et al., } \\
\text { 2018; Tang et al., 2019) }\end{array}$ & $765 / 1411$ & Quartile1 & 103.9-112 & 0.08 & $(-0.20,0.35)$ & 0.59 \\
\hline & $\begin{array}{l}6 \text { (Scacchi et al., 1998; Hoshino et al., 2002; Solfrizzi et al., } \\
\text { 2002; Panza et al., 2003; Reitz et al., 2004; Mamo et al., 2008) }\end{array}$ & $514 / 2521$ & Quartile2 & $112-121$ & -0.26 & $(-0.58,0.06)$ & 0.11 \\
\hline & $\begin{array}{l}6 \text { (Kuo et al., 1998; Caramelli et al., 1999; Lesser et al., 2001; } \\
\text { Yavuz et al., 2008; Ban et al., 2009; Chen et al., 2019) }\end{array}$ & $578 / 412$ & Quartile3 & $121-137$ & 0.98 & $(0.13,1.82)$ & 0.02 \\
\hline & $\begin{array}{l}7 \text { (Lehtonen and Luutonen, 1986; Paragh et al., 2002; Ryglewicz } \\
\text { et al., 2002; Cacabelos et al., 2003; Wolf et al., 2004; Wehr } \\
\text { et al., 2006; Macesic et al., 2017) }\end{array}$ & $409 / 423$ & Quartile4 & $\geq 137$ & 0.62 & $(0.18,1.06)$ & $<0.01$ \\
\hline \multirow[t]{2}{*}{ Sample size (n) } & $\begin{array}{l}11 \text { (Lehtonen and Luutonen, 1986; Caramelli et al., 1999; Lesser } \\
\text { et al., 2001; Paragh et al., 2002; Ryglewicz et al., 2002; Solfrizzi } \\
\text { et al., 2002; Panza et al., 2003; Wolf et al., 2004; Mamo et al., } \\
\text { 2008; Kouzuki et al., 2018; Shafagoj et al., 2018) }\end{array}$ & $359 / 340$ & Small & $<50$ & 0.13 & $(-0.30,0.56)$ & 0.56 \\
\hline & $\begin{array}{l}15 \text { (Kuo et al., 1998; Scacchi et al., 1998; Moroney et al., 1999; } \\
\text { Hoshino et al., 2002; Cacabelos et al., 2003; Reitz et al., 2004; } \\
\text { Watanabe et al., 2005; Yamamoto et al., 2005; Wehr et al., } \\
\text { 2006; Yavuz et al., 2008; Ban et al., 2009; Warren et al., 2012; } \\
\text { Macesic et al., 2017; Chen et al., 2019; Tang et al., 2019) }\end{array}$ & $1907 / 4427$ & Large & $\geq 50$ & 0.44 & $(0.16,0.72)$ & $<0.01$ \\
\hline
\end{tabular}

yrs, years; SMD, standard mean difference; Cl, confidence interval.

$0.82 \sim 1.26, p=0.88)$ and CVD (OR $=1.28,95 \%$ CI $0.61 \sim 2.70$, $p=0.51$ ) between $\mathrm{AD}$ and non-dementia controls; whilst there was a positive correlation of age $(\mathrm{SMD}=0.62,95 \% \mathrm{CI} 0.28 \sim 0.95$, $p<0.01)$ and a inverse correlation of BMI (SMD $=-0.31,95 \%$ CI $-0.48 \sim-0.13, p<0.01$ ) between AD and controls. Subgroup analysis on age showed LDL-c levels in $\mathrm{AD}$ patients aged 60 to 70 were higher than that of non-dementia $(60 \leq$ age $<70$ : SMD $=0.8,95 \% \mathrm{CI} 0.23 \sim 1.37, p<0.01)$; but no association between the SMD of AD in LDL-c and age over 70 was noted across the studies $(70 \leq$ age $<77$ : $\mathrm{SMD}=-0.02,95 \% \mathrm{CI}-0.39 \sim 0.34, p=$ 9.0; $77 \leq$ age $<80$ : $\mathrm{SMD}=0.15,95 \% \mathrm{CI}-0.17 \sim 0.47, p=0.35$; $\geq 80$ : SMD $=0.53,95 \%$ CI $-0.04 \sim 1.11, p=0.07$; Table 3). The concentrations of LDL-c during the quintile interval of $3 \sim 4$ were positively associated with $\mathrm{AD}(121 \leq$ concentration $<137$ : SMD $=0.98,95 \% \mathrm{CI} 0.13 \sim 1.82, p=0.02 ; \geq 137: \mathrm{SMD}=0.62,95 \% \mathrm{CI}$ $0.18 \sim 1.06, p<0.01)$; however, there was no correlation between $\mathrm{AD}$ and LDL-c within the quintile interval of $1 \sim 2(103.9 \leq$ concentration $<112$ : $\mathrm{SMD}=0.08,95 \% \mathrm{CI}-0.20 \sim 0.35, p=0.59$; $112 \leq$ concentration $<121$ : SMD $=-0.26,95 \% \mathrm{CI}-0.58 \sim 0.06$, $p=0.11$; Table 3). We found an association between LDL-c levels and $\mathrm{AD}$ in studies with large sample size $(\geq 50$ : $\mathrm{SMD}=0.44$, $95 \%$ CI $0.16 \sim 0.72, p<0.01)$; whilst no association was found in studies with small sample size $(<50$ : SMD $=0.13,95 \% \mathrm{CI}$ $-0.30 \sim 0.56, p=0.56$; Table 3).

\section{Sensitivity Analysis and Publication Bias}

Sensitivity analyses showed that no single study exerted substantial influence on the pooled effect size after sequentially omitting a study (Figure 4). As shown in Figure 5, there was no significant evidence of publication bias according to the results of Egger's test $(p=0.084)$.

\section{DISCUSSION}

In our comprehensive meta-analysis, 26 eligible studies involving 7,033 participants were summarized to estimate the impact of serum LDL-c on the incident of Alzheimer's disease. To our best acknowledgment, this is the first systematic overview that reported an assessment of LDL-c for AD risk in the absence of cholesterol-lowering drugs and vascular risk factors (e.g., smoking, hypertension, diabetes mellitus, and CVD). Although the heterogeneity across the included studies indicated conflicting views of previous evidence, the pooled effect size exhibited a significant increase in risk of $\mathrm{AD}$ for individuals with higher levels of LDL-c. Furthermore, we conducted stratified analyses to explore the underlying relationship between serum LDL-c and AD incidence in a more in-depth way, and meanwhile, tried 

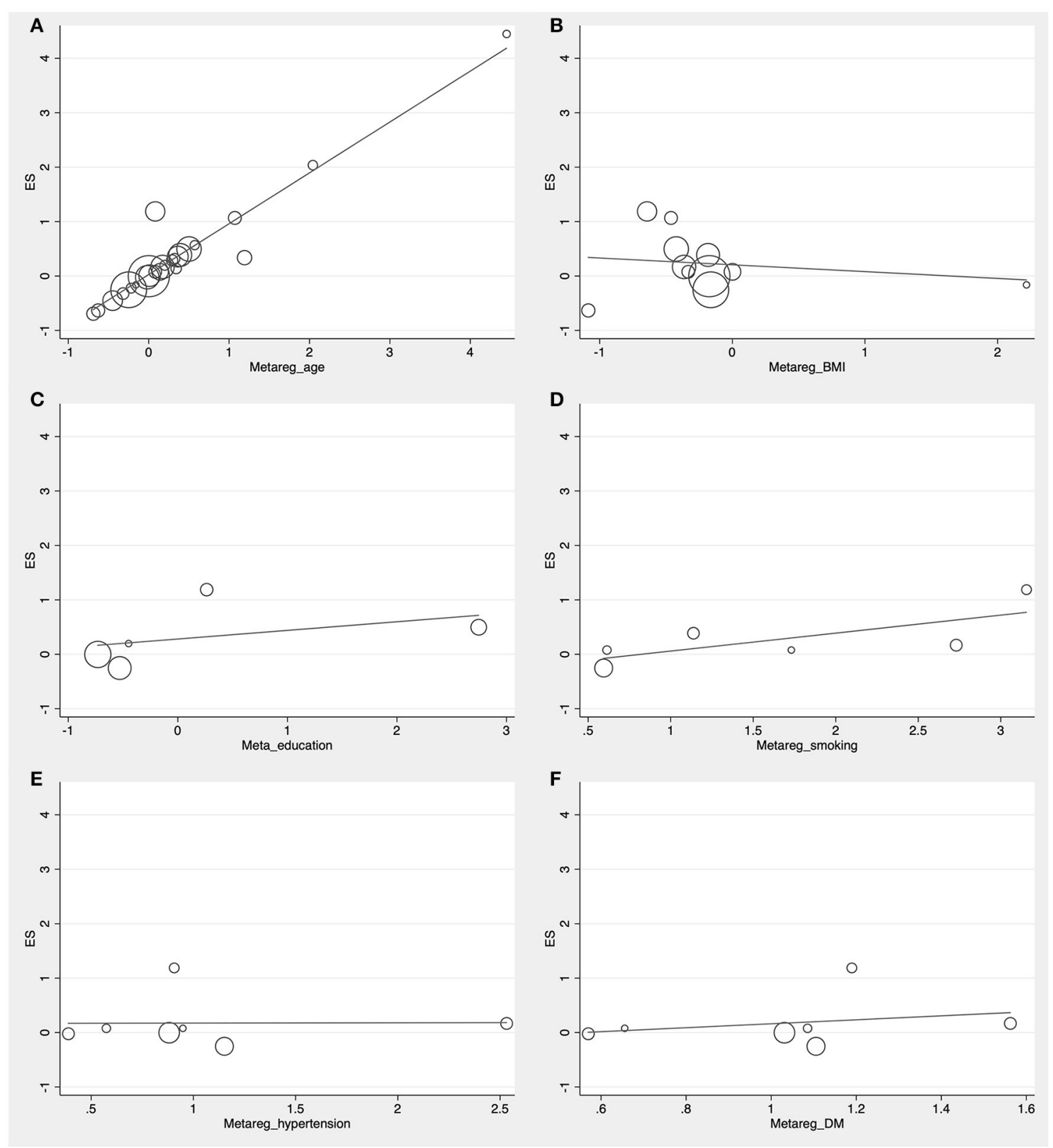

FIGURE 3 | Forest plots of the meta-regression analyses on age (A), body mass index (B), education (C), smoking (D), hypertension (E), and diabetes mellitus (F) in relation to LDL-c levels between Alzheimer's disease and non-dementia. ES, effect size.

to find out the factors affecting its correlation by metaregression analysis.

The results emerging from this meta-analysis revealed that there were higher levels of LDL-c in patients with $\mathrm{AD}$ than that of non-dementia controls, implying serum LDL-c likely to be a risk factor for $\mathrm{AD}$. Consistent with our results, an observational study showed that the higher LDL-c level measured before the diagnosis of dementia, the faster the memory loss of AD patients (Helzner et al., 2009). Epidemiologic and experimental data demonstrated that serum LDL-c was involved in the development of Alzheimer amyloid pathology (Pappolla et al., 2003). In practice, however, lipoprotein-bound cholesterol does not flow directly from the bloodstream into the brain, but instead ACTS through an intermediate metabolite linking LDL-c closely to the onset of $\mathrm{AD}$. The neurotoxic oxysterol 27-hydroxycholesterol (27-OHC) is such an extracerebral metabolite of cholesterol that crosses the blood-brain barrier. Evidence from AD patients and APP/PS1 mice confirmed that excessive flux of $27-\mathrm{OHC}$ entering the brain led to enhanced deposition of $\beta$-amyloid (Zhang et al., 2019) and 


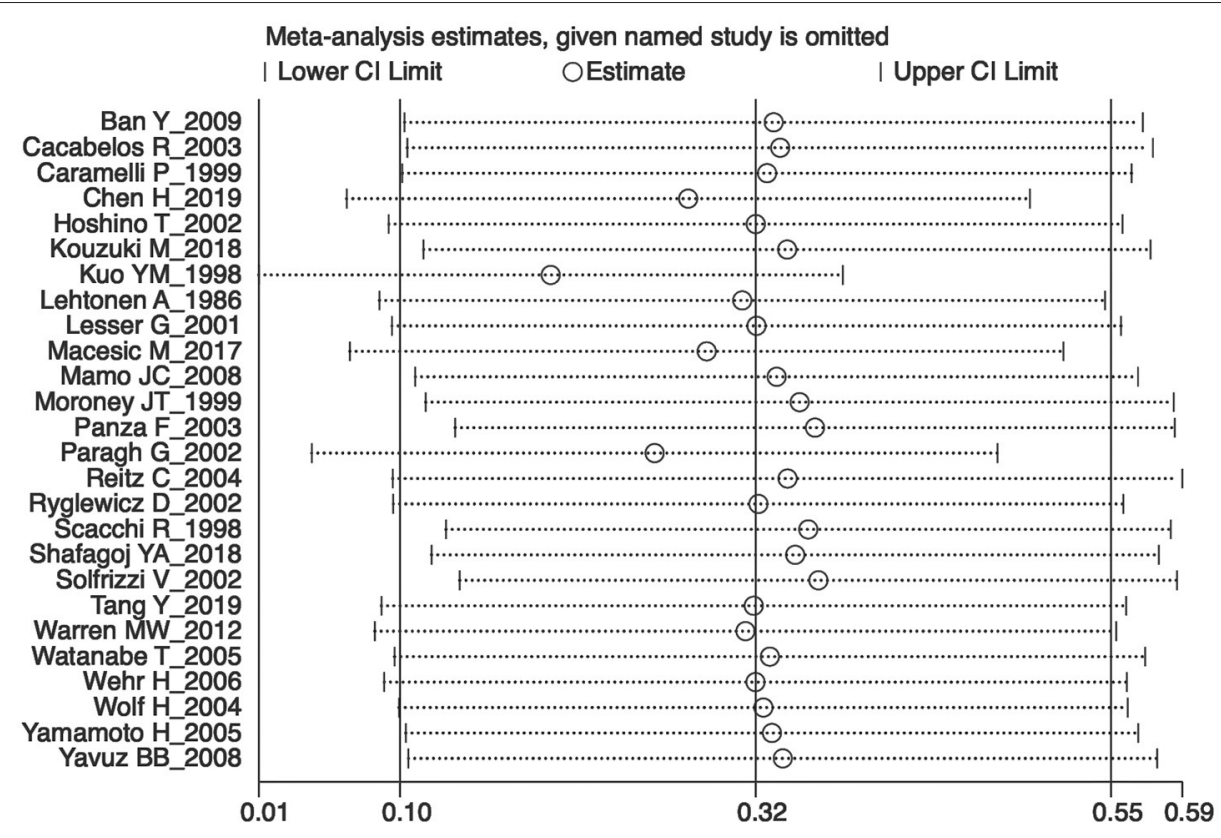

FIGURE 4 | The plot in the sensitivity analysis of current meta-analysis (given named study was omitted).

reduced brain glucose uptake (Ismail et al., 2015). In primary cultures of rat hippocampal cells, 27-OHC decreased expression of the "memory protein" Arc (activity regulated cytoskeleton associated protein), and thus to accelerating the process of neurodegeneration such as AD (Björkhem et al., 2009; Heverin et al., 2015). Additionally, a population-based autopsy study revealed an accumulation of $27-\mathrm{OHC}$ in brains of $\mathrm{AD}$ patients, which partially supported its role as a major pathogenetic factor (Shafaati et al., 2011). This accumulation was a subsequent consequence of elevated LDL-c level in the circulation; in turn, lowering LDL-c level was supposed to have a causal effect on the reduction of $\mathrm{AD}$ risk, as validated by a large-scale Mendelian randomization study of 111,194 individuals (Benn et al., 2017).

Qualitative determination of the association between $\mathrm{AD}$ risk and elevated LDL-c level is not sufficient; moreover, quantifying the impact of alterations in LDL-c concentration on the incidence of $\mathrm{AD}$ appears to be more meaningful. After the exclusion of differences in relation to vascular risk factors (e.g., smoking, hypertension, diabetes mellitus, and CVD) between AD patients and non-dementia controls, subgroup analysis on concentration showed that LDL-c level above $121 \mathrm{mg} / \mathrm{dl}$ was positively related to $\mathrm{AD}$; whereas no association was found when LDL-c level dropped to $103.9-121 \mathrm{mg} / \mathrm{dl}$. Due to the lack of relevant data in the selected studies, we do not certain whether LDL-c level below $103.9 \mathrm{mg} / \mathrm{dl}$ has implications on AD. Previous study showed that reduction of LDL-c level by mutations in PCSK9 and 3hydroxy-3-methylglutaryl-CoA reductase (HMGCR) exerted no causal effect on high risk of AD (Benn et al., 2017). It can be argued that probably a small amounts of AD patients with PCSK9 and HMGCR variants were recruited in the eligible studies examined in the current meta-analysis, which may partially offset our findings. If that's the case, elevated LDL-c level is more strongly related to risk of $\mathrm{AD}$. However, it has been suggested that extremely low levels of cholesterol are potentially detrimental to neurocognitive function. The reason may be that cholesterol accounting for $85 \%$ of the brain is an essential component for the synaptogenesis of myelin axons (Björkhem and Meaney, 2004; Krakowski and Czobor, 2011). Evidence from the Framingham Heart Study demonstrated that normal cognitive performance required a certain level of cholesterol to maintain (Elias et al., 2005), so the reduction of LDL-c to different levels is associated with either cognitive impairment or improvement (Rojas-Fernandez et al., 2014). Even though there is some volatility in LDL-c level due to the average data extracted, the results of subgroup analysis would provide certain guiding significance for the treatment of $\mathrm{AD}$ with LDL-c lowering; more specifically, it is reasonable to assume that regulation of LDL-c levels between 103.9 and $121 \mathrm{mg} / \mathrm{dl}$ might reduce or eliminate the adverse effect of LDL-c on the pathogenesis of $\mathrm{AD}$.

Furthermore, confounding factors that possibly influence the association between LDL-c and AD needed to be investigated due to the high heterogeneity among studies. The data of included studies were sorted out for gender, age, BMI, education, and those except four took account of vascular risk factors such as smoking, hypertension, diabetes mellitus, and CVD. Among these baseline characteristics, both age and BMI showed statistical differences between $\mathrm{AD}$ patients and non-dementia controls; that is, $\mathrm{AD}$ was positively correlated with age and negatively related to BMI, which was in line with previous results (Helzner et al., 2009; Nordestgaard et al., 2017). However, low BMI was 


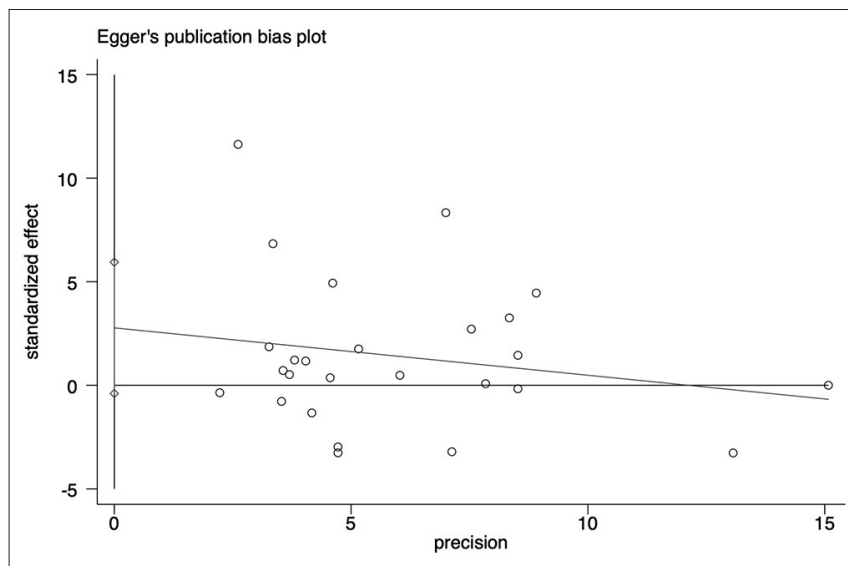

FIGURE 5 | Egger's funnel plot to detect risk of publication bias in the meta-analysis.

not a causal risk factor for $\mathrm{AD}$ and that the corresponding observational relationship were possibly attributed to reverse causation or confounding (Nordestgaard et al., 2017). Further meta-regression analysis revealed that not BMI and other confounders including education, smoking, hypertension, and diabetes mellitus, but the age and CVD exerted an impact on the relationship between LDL-c and risk of $\mathrm{AD}$. Consequently, only age had both positive results and was considered more of an effect modifier than a confounder, which might explain $92.41 \%$ of the variance seen in this type of meta-analysis. Age imposes the greatest risk for dementia and mortality (Vermunt et al., 2019), and inhibition interventions of aging are possibly linked to LDL-c. Mice treated with metformin, for example, enjoyed an extended span of health and longevity as well as reduction in LDL-c (Martin-Montalvo et al., 2013). In current meta-analysis, subgroup analysis on age showed LDL-c levels higher in AD patients aged 60-70 than that of non-dementia, but no association of $\mathrm{AD}$ with LDL-c in patients over the age of 70 , indicating that the neurotoxic role of LDL-c in AD may only apply to individuals aged 6070 and gradually subsides with advancing age. These results were consistent with the Washington Heights/Inwood Columbia Aging Project (Helzner et al., 2009), presumably that enzymatic activity and mRNA level of pancreatic lipase decreased with advancing age (Yamamoto et al., 2014), so did lipid ingestion and absorption, and thus to abnormal LDL-c metabolism. Cardiovascular disease contributes to $\mathrm{AD}$, and both of them mutually affect respective pathological processes (Liu et al., 2014; Bleckwenn et al., 2017), which is consistent with our findings of meta-regression. Previous studies demonstrated that patients with $\mathrm{AD}$ are prone to arteriosclerotic microangiopathy, whilst the amounts of senile plaques in brains of patients with CVD are much higher (Sparks et al., 1990; Casserly and Topol, 2004). In addition, subgroup analysis of large sample studies revealed a positive association of LDL-c with AD risk, but no correlation was in subgroup analysis of small sample studies, implying that sample size-related differences had an implication on its correlation. As the precision of summary estimate improves with the increase of sample size, large sample studies more accurately represent the reliability of the relationship between LDL-c and AD. Further studies with LDL-c below $103.9 \mathrm{mg} / \mathrm{dl}$ at baseline or after statins therapy in large sample cohorts are required to replenish the association of $\mathrm{AD}$ incident with LDL-c.

\section{Limitations}

There exist noteworthy limitations on our study. Variability in diagnostic criteria of $\mathrm{AD}$ between data sets may affect our results. Moreover, vascular dementia might misclassify as $\mathrm{AD}$ due to the overlaps in symptomatology, pathophysiology and risk factors, and approximately one-third of cases diagnosed with $\mathrm{AD}$ while alive have no pathological evidence of the disease at autopsy. Although statins may have a medication-specific effect on $\mathrm{AD}$, there is possibly a bias to exclude a large number of studies on the use of statins. The statistical heterogeneity was evident across the individual studies, which might be related to differences in age, concentration of LDL-c and sample size. The results of subgroup analyses were not absolutely conclusive and should be interpreted with caution, as data on age and LDL-c concentration were obtained from the mean value of cases in each study. Differences in general characteristics (e.g., age, CVD) and genetic factors (e.g., APOE4 allele, variants in PCSK9 and HMGCR) between $\mathrm{AD}$ patients and non-dementia controls may affect outcomes. Other sources of heterogeneity may be derived from differences in detection methods, cut-off value of LDL-c, dietary intake and exercise habits among various studies. Although Egger's test implied no publication bias in the meta-analysis, systematic reviews in favor of positive findings may lead to potential bias.

\section{CONCLUSIONS}

Considering the results of this study, we may resumptively claim that elevated concentration of LDL-c $(>121 \mathrm{mg} / \mathrm{dl})$ is a potential risk factor for $\mathrm{AD}$. This strong association is significant in patients with AD aged 60-70 years, but vanishes with increasing age. The present meta-analysis provides a promising strategy for reducing the risk of $\mathrm{AD}$ in patients with hyperlipidemia, which may be achieved by regulating LDL-c concentration between 103.9 and $121 \mathrm{mg} / \mathrm{dl}$ with statins. Prospective studies that exclude potential confounders, more scientific design, and adequate long-term follow-up are needed to validate this hypothesis.

\section{DATA AVAILABILITY STATEMENT}

The raw data supporting the conclusions of this article will be made available by the authors, without undue reservation, to any qualified researcher.

\section{AUTHOR CONTRIBUTIONS}

The study was conceived by CZ and ZZ. Literature search and selection were conducted by $\mathrm{XZ}$ and $\mathrm{YL}$ The data were extracted and analyzed by KK, RZ, JX, and CL. The rough manuscript was drafted by ZZ, MZ, and CZ. All authors 
corrected and approved the final version of the manuscript after review.

\section{FUNDING}

The study was supported by the National Natural Science Foundation of China (No. 81372104); the Natural Science Foundation of Liaoning Province (No. 20180540150); the Shenyang Population and Health Technical Critical Special Project (No. F16-206-9-01); the Program of the Distinguished Professor of Liaoning Province (CZ).

\section{ACKNOWLEDGMENTS}

All the authors of this article should be appreciated sincerely.

\section{SUPPLEMENTARY MATERIAL}

The Supplementary Material for this article can be found online at: https://www.frontiersin.org/articles/10.3389/fnagi. 2020.00005/full\#supplementary-material

Supplementary Table 1 | The developed guidelines of preferred reporting items for systematic reviews and meta-analyses (PRISMA).

Supplementary Table 2 | Other supplementary baseline characteristics of included studies. n, number; BMI, body mass index; HBP, high blood pressure; CVD, cardiovascular disease; NR, Not reported.

Supplementary Figure 1 | Forest plots of the meta-regression analyses on CVD in relation to LDL-c levels between Alzheimer's disease and non-dementia. CVD, cardiovascular disease; ES, effect size.

Supplementary Figure 2 | Forest plots of the comparisons using the fixed-effect model in relation to LDL-c levels between Alzheimer's disease and non-dementia. $\mathrm{Cl}$, confidence interval.

\section{REFERENCES}

American Psychiatric Association (1980). Diagnostic and Statistical Manual of Mental Disorders, 3rd Edn. Washington, DC: American Psychiatric Association.

American Psychiatric Association (1987). Diagnostic and Statistical Manual of Mental Disorders, 3rd Edn. Washington, DC: American Psychiatric Association. American Psychiatric Association (1994). Diagnostic and Statistical Manual of Mental Disorders: DSM-IV, 4th Edn. Washington, DC: American Psychiatric Association.

American Psychiatric Association (2013). Diagnostic and Statistical Manual of Mental Disorders, DSM-5, 5th Edn. Washington, DC: American Psychiatric Association. doi: 10.1176/appi.books.9780890425596

Ban, Y., Watanabe, T., Suguro, T., Matsuyama, T. A., Iso, Y., Sakai, T., et al. (2009). Increased plasma urotensin-II and carotid atherosclerosis are associated with vascular dementia. J. Atheroscler. Thromb. 16, 179-187. doi: 10.5551/jat.E608

Barnes, D. E., and Yaffe, K. (2011). The projected effect of risk factor reduction on Alzheimer's disease prevalence. Lancet Neurol. 10, 819-828. doi: 10.1016/S1474-4422(11)70072-2

Benn, M., Nordestgaard, B. G., Frikke-Schmidt, R., Tybjærg-Hansen, A. (2017). Low LDL cholesterol, PCSK9 and HMGCR genetic variation, and risk of Alzheimer's disease and Parkinson's disease: Mendelian randomisation study. BMJ 357:j1648. doi: 10.1136/bmj.j1648

Björkhem, I., Cedazo-Minguez, A., Leoni, V., and Meaney, S. (2009). Oxysterols and neurodegenerative diseases. Mol. Aspects Med. 30, 171-179. doi: 10.1016/j.mam.2009.02.001

Björkhem, I., and Meaney, S. (2004). Brain cholesterol: long secret life behind a barrier. Arterioscler Thromb Vasc. Biol. 24, 806-815. doi: 10.1161/01.ATV.0000120374.59826.1b

Bleckwenn, M., Kleineidam, L., Wagner, M., Jessen, F., Weyerer, S., Werle, J., et al. (2017). Impact of coronary heart disease on cognitive decline in Alzheimer's disease: a prospective longitudinal cohort study in primary care. Br. J. Gen. Pract. 67, e111-e117. doi: 10.3399/bjgp16X688813

Cacabelos, R., Fernández-Novoa, L., Lombardi, V., Corzo, L., Pichel, V., and Kubota, Y. (2003). Cerebrovascular risk factors in Alzheimer's disease: brain hemodynamics and pharmacogenomic implications. Neurol Res. 25, 567-580. doi: 10.1179/016164103101202002

Caramelli, P., Nitrini, R., Maranhão, R., Lourenço, A. C., Damasceno, M. C., Vinagre, C., et al. (1999). Increased apolipoprotein B serum concentration in Alzheimer's disease. Acta Neurol. Scand. 100, 61-63. doi: 10.1111/j.1600-0404.1999.tb00724.x

Casserly, I., and Topol, E. J. (2004). Convergence of atherosclerosis and Alzheimer's disease: inflammation, cholesterol, and misfolded proteins. Lancet 363, 1139-1146. doi: 10.1016/S0140-6736(04)15900-X

Chen, H., Du, Y., Liu, S., Ge, B., Ji, Y., and Huang, G. (2019). Association between serum cholesterol levels and Alzheimer's disease in China a case-control study. Int. J. Food Sci. Nutr. 70, 405-411. doi: 10.1080/09637486.2018.1508426

Davidson, J. E., Lockhart, A., Amos, L., Stirnadel-Farrant, H. A., Mooser, V., Sollberger, M., et al. (2012). Plasma lipoprotein-associated phospholipase A2 activity in Alzheimer's disease, amnestic mild cognitive impairment, and cognitively healthy elderly subjects a cross-sectional study. Alzheimers Res. Ther. 4:51. doi: 10.1186/alzrt154

Durazzo, T. C., Mattsson, N., Weiner, M. W., and Alzheimer's Disease Neuroimaging Initiative. (2014). Smoking and increased Alzheimer's disease risk: a review of potential mechanisms. Alzheimers Dement. 10, S122-S145. doi: 10.1016/j.jalz.2014.04.009

Egger, M., Davey Smith, G., Schneider, M., and Minder, C. (1997). Bias in meta-analysis detected by a simple, graphical test. BMJ 315, 629-634. doi: 10.1136/bmj.315.7109.629

Elias, P. K., Elias, M. F., D’Agostino, R. B., Sullivan, L. M., and Wolf, P. A. (2005). Serum cholesterol and cognitive performance in the Framingham Heart Study. Psychosom. Med. 67, 24-30. doi: 10.1097/01.psy.0000151745.67285.c2

Ference, B. A., Ginsberg, H. N., Graham, I., Ray, K. K., Packard, C. J., Bruckert, E., et al. (2017). Low-density lipoproteins cause atherosclerotic cardiovascular disease. 1. Evidence from genetic, epidemiologic, and clinical studies. A consensus statement from the European Atherosclerosis Society Consensus Panel. Eur. Heart J. 38, 2459-2472. doi: 10.1093/eurheartj/ehx144

Helzner, E. P., Luchsinger, J. A., Scarmeas, N., Cosentino, S., Brickman, A. M., Glymour, M. M., et al. (2009). Contribution of vascular risk factors to the progression in Alzheimer disease. Arch. Neurol. 66, 343-348. doi: 10.1001/archneur.66.3.343

Heverin, M., Maioli, S., Pham, T., Mateos, L., Camporesi, E., Ali, Z., et al. (2015). 27-Hydroxycholesterol mediates negative effects of dietary cholesterol on cognition in mice. Behav. Brain. Res. 278, 356-359. doi: 10.1016/j.bbr.2014.10.018

Higgins, J. P., and Thompson, S. G. (2002). Quantifying heterogeneity in a meta-analysis. Stat Med. 21, 1539-1558. doi: 10.1002/sim.1186

Higgins, J. P., Thompson, S. G., Deeks, J. J., and Altman, D. G. (2003). Measuring inconsistency in meta-analyses. BMJ 327, 557-560. doi: 10.1136/bmj.327.7414.557

Hoshino, T., Kamino, K., and Matsumoto, M. (2002). Gene dose effect of the APOE-epsilon 4 allele on plasma HDL cholesterol level in patients with Alzheimer's disease. Neurobiol. Aging 23, 41-45. doi: 10.1016/S0197-4580(01)00252-4

Ismail, M. A., Mateos, L., Maioli, S., Merino-Serrais, P., Ali, Z., Lodeiro, M., et al. (2015). 27-Hydroxycholesterol impairs neuronal glucose uptake through an IRAP/GLUT4 system dysregulation. J. Exp. Med. 214, 699-717. doi: 10.1084/jem.20160534

Jeong, W., Lee, H., Cho, S., and Seo, J. (2019). ApoE4-induced cholesterol dysregulation and its brain cell type-specific implications in the pathogenesis of Alzheimer's disease. Mol. Cells 42, 739-746. doi: 10.14348/molcells.2019.0200

Kapogiannis, D., Mustapic, M., Shardell, M. D., Berkowitz, S. T., Diehl, T. C., Spangler, R. D., et al. (2019). Association of extracellular vesicle biomarkers 
with Alzheimer disease in the Baltimore Longitudinal Study of Aging. JAMA Neurol. 76, 1340-1351. doi: 10.1001/jamaneurol.2019.2462

Kouzuki, M., Nagano, M., Suzuki, T., Katsumata, Y., Nakamura, S., Takamura, A., et al. (2018). Cerebrospinal fluid biomarkers of Alzheimer's disease are associatedwith carotid plaque score and hemodynamics in intraand extra-cranialarteries on ultrasonography. J. Clin. Neurosci. 49, 32-36. doi: 10.1016/j.jocn.2017.12.006

Krakowski, M., and Czobor, P. (2011). Cholesterol and cognition in schizophrenia: a double-blind study of patients randomized to clozapine, olanzapine and haloperidol. Schizophr Res. 130, 27-33. doi: 10.1016/j.schres.2011. 04.005

Kuo, Y. M., Emmerling, M. R., Bisgaier, C. L., Essenburg, A. D., Lampert, H. C., Drumm, D., et al. (1998). Elevated low-density lipoprotein in Alzheimer's disease correlates with brain abeta 1-42 levels. Biochem. Biophys. Res. Commun. 252, 711-715. doi: 10.1006/bbrc.1998.9652

Lehtonen, A., and Luutonen, S. (1986). High-density lipoprotein cholesterol levels of very old people in the diagnosis of dementia. Age Ageing 15, 267-270. doi: 10.1093/ageing/15.5.267

Lesser, G., Kandiah, K., Libow, L. S., Likourezos, A., Breuer, B., Marin, D., et al. (2001). Elevated serum total and LDL cholesterol in very old patients with Alzheimer's disease. Dement Geriatr. Cogn. Disord. 12, 138-145. doi: $10.1159 / 000051248$

Lesser, G. T., Haroutunian, V., Purohit, D. P., Schnaider Beeri, M., Schmeidler, J., Honkanen, L., et al. (2009). Serum lipids are related to Alzheimer's pathology in nursing home residents. Dement Geriatr. Cogn. Disord. 27, 42-49. doi: $10.1159 / 000189268$

Li, H., Zhou, J., Yue, Z., Feng, L., Luo, Z., Chen, S., et al. (2017). A complex association between ABCA7 genotypes and blood lipid levels in Southern Chinese Han patients of sporadic Alzheimer's disease. J. Neurol. Sci. 382, 13-17. doi: 10.1016/j.jns.2017.09.016

Lin, Y. T., Seo, J., Gao, F., Feldman, H. M., Wen, H. L., Penney, J., et al. (2018). APOE4 causes widespread molecular and cellular alterations associated with Alzheimer's disease phenotypes in human iPSC-derived brain cell types. Neuron 98, 1141-1154.e7. doi: 10.1016/j.neuron.2018.05.008

Liu, G., Yao, L., Liu, J., Jiang, Y., Ma, G., Genetic and Environmental Risk for Alzheimer's disease (GERAD1) Consortium, et al. (2014). Cardiovascular disease contributes to Alzheimer's disease: evidence from large-scale genome-wide association studies. Neurobiol Aging 35, 786-792. doi: 10.1016/j.neurobiolaging.2013.10.084

Macesic, M., Lalic, N. M., Kostic, V. S., Jotic, A., Lalic, K., Stefanova, E., et al. (2017). Impaired insulin sensitivity and secretion in patients with Alzheimer's disease: the relationship with other atherosclerosis risk factors. Curr. Vasc. Pharmacol. 15, 158-166. doi: 10.2174/1570161114666160905170644

Mamo, J. C., Jian, L., James, A. P., Flicker, L., Esselmann, H., Wiltfang, J., et al. (2008). Plasma lipoprotein beta-amyloid in subjects with Alzheimer's disease or mild cognitive impairment. Ann. Clin. Biochem. 45(Pt 4), 395-403. doi: 10.1258/acb.2008.007214

Martinez-Valbuena, I., Valenti-Azcarate, R., Amat-Villegas, I., Riverol, M., Marcilla, I., de Andrea, C. E., et al. (2019). Amylin as a potential link between type 2 diabetes and Alzheimer's disease. Ann. Neurol. 86, 539-551. doi: $10.1002 /$ ana. 25570

Martin-Montalvo, A., Mercken, E. M., Mitchell, S. J., Palacios, H. H., Mote, P. L., Scheibye-Knudsen, M., et al. (2013). Metformin improves healthspan and lifespan in mice. Nat. Commun. 4:2192. doi: 10.1038/ncomms3192

McKhann, G., Drachman, D., Folstein, M., Katzman, R., Price, D., and Stadlan, E. M. (1984). Clinical diagnosis of Alzheimer's disease: report of the NINCDSADRDA Work Group under the auspices of Department of Health and Human Services Task Force on Alzheimer's Disease. Neurology 34, 939-944. doi: 10.1212/WNL.34.7.939

Moher, D., Liberati, A., Tetzlaff, J., Altman, D. G., and PRISMA Group. (2009). Preferred reporting items for systematic reviews and meta-analyses: the PRISMA statement. PLoS Med. 6:e1000097. doi: 10.1371/journal.pmed.1000097

Moroney, J. T., Tang, M. X., Berglund, L., Small, S., Merchant, C., Bell, K., et al. (1999). Low-density lipoprotein cholesterol and the risk of dementia with stroke. JAMA 282, 254-260. doi: 10.1001/jama.282.3.254

Nordestgaard, L. T., Tybjærg-Hansen, A., Nordestgaard, B. G., and FrikkeSchmidt, R. (2017). Body mass index and risk of Alzheimer's disease: a
Mendelian randomization study of 399,536 individuals. J. Clin. Endocrinol. Metab. 102, 2310-2320. doi: 10.1210/jc.2017-00195

Panza, F., Solfrizzi, V., Colacicco, A. M., Basile, A. M., D'Introno, A., Capurso, C., et al. (2003). Apolipoprotein E (APOE) polymorphism influences serum APOE levels in Alzheimer's disease patients and centenarians. Neuroreport 14, 605-608. doi: 10.1097/00001756-200303240-00016

Pappolla, M. A., Bryant-Thomas, T. K., Herbert, D., Pacheco, J., Fabra Garcia, M., Manjon, M., et al. (2003). Mild hypercholesterolemia is an early risk factor for the development of Alzheimer amyloid pathology. Neurology 61, 199-205. doi: 10.1212/01.WNL.0000070182.02537.84

Paragh, G., Balla, P., Katona, E., Seres, I., Egerházi, A., and Degrell, I. (2002). Serum paraoxonase activity changes in patients with Alzheimer's disease and vascular dementia. Eur. Arch. Psychiatry. Clin. Neurosci. 252, 63-67. doi: $10.1007 /$ s004060200013

Prince, M., Bryce, R., Albanese, E., Wimo, A., Ribeiro, W., and Ferri, C. P. (2013). The global prevalence of dementia: a systematic review and metaanalysis. Alzheimers Dement. 9, 63-75.e2. doi: 10.1016/j.jalz.2012.11.007

Reitz, C., and Mayeux, R. (2014). Alzheimer disease: epidemiology, diagnostic criteria, risk factors and biomarkers. Biochem Pharmacol. 88, 640-651. doi: 10.1016/j.bcp.2013.12.024

Reitz, C., Tang, M. X., Luchsinger, J., and Mayeux, R. (2004). Relation of plasma lipids to Alzheimer disease and vascular dementia. Arch. Neurol. 61, 705-714. doi: 10.1001/archneur.61.5.705

Rojas-Fernandez, C. H., Goldstein, L. B., Levey, A. I., Taylor, B. A., Bittner, V., and The National Lipid Association's Safety Task Force. (2014). An assessment by the Statin Cognitive Safety Task Force: 2014 update. J. Clin. Lipidol. 8, S5-16. doi: 10.1016/j.jacl.2014.02.013

Ryglewicz, D., Rodo, M., Kunicki, P. K., Bednarska-Makaruk, M., Graban, A., Lojkowska, W., et al. (2002). Plasma antioxidant activity and vascular dementia. J. Neurol. Sci. 203, 195-197. doi: 10.1016/S0022-510X(02)00290-3

Sabatine, M. S., Giugliano, R. P., Wiviott, S. D., Raal, F. J., Blom, D. J., Robinson, J., et al. (2015). Efficacy and safety of evolocumab in reducing lipids and cardiovascular events. N. Engl. J. Med. 372, 1500-1509. doi: 10.1056/NEJMoa1500858

Scacchi, R., De Bernardini, L., Mantuano, E., Vilardo, T., Donini, L. M., Ruggeri, M., et al. (1998). DNA polymorphisms of apolipoprotein B and angiotensin Iconverting enzyme genes and relationships with lipid levels in Italian patients with vascular dementia or Alzheimer's disease. Dement Geriatr. Cogn. Disord. 9, 186-190. doi: 10.1159/000017045

Schaefer, S. (2014). ACP Journal Club. Review: in older patients without CVD, statins reduce MI and stroke but not all-cause mortality. Ann. Intern. Med. 160:JC8. doi: 10.7326/0003-4819-160-10-201405200-02008

Shafaati, M., Marutle, A., Pettersson, H., Lövgren-Sandblom, A., Olin, M., Pikuleva, I., et al. (2011). Marked accumulation of 27-hydroxycholesterol in the brains of Alzheimer's patients with the Swedish APP 670/671 mutation. J. Lipid. Res. 52, 1004-1010. doi: 10.1194/jlr.M014548

Shafagoj, Y. A., Naffa, R. G., El-Khateeb, M. S., Abdulla, Y. L., Al-Qaddoumi, A. A., Khatib, F. A., et al. (2018). APOE Gene polymorphism among Jordanian Alzheimer's patients with relation to lipid profile. Neurosciences 23, 29-34. doi: 10.17712/nsj.2018.1.20170169

Sindi, S., Kåreholt, I., Johansson, L., Skoog, J., Sjöberg, L., Wang, H. X., et al. (2018). Sleep disturbances and dementia risk: a multicenter study. Alzheimers Dement. 14, 1235-1242. doi: 10.1016/j.jalz.2018.05.012

Solfrizzi, V., Panza, F., Colacicco, A. M., D'introno, A., Capurso, C., Gatti, G., et al. (2002). Serum apolipoprotein E levels in Alzheimer's disease and extreme longevity. Arch. Gerontol. Geriatr. 35, 345-352. doi: 10.1016/S0167-4943(02)00126-7

Sparks, D. L., Hunsaker, J. C., Scheff, S. W., Kryscio, R. J., Henson, J. L., and Markesbery, W. R. (1990). Cortical senile plaques in coronary artery disease, aging and Alzheimer's disease. Neurobiol Aging 11, 601-607. doi: 10.1016/0197-4580(90)90024-T

Tang, Y., Li, Y. M., Zhang, M., Chen, Y. Q., and Sun, Q. (2019). ع3/4 genotype of the apolipoprotein $\mathrm{E}$ is associated with higher risk of Alzheimer's disease in patients with type 2 diabetes mellitus. Gene 703, 65-70. doi: 10.1016/j.gene.2019.03.024

Vermunt, L., Sikkes, S. A. M., van den Hout, A., Handels, R., Bos, I., van der Flier, W. M., et al. (2019). Duration of preclinical, prodromal, and dementia stages of Alzheimer's disease in relation to age, sex, and APOE genotype. Alzheimers Dement. 15, 888-898. doi: 10.1016/j.jalz.2019.04.001 
Warren, M. W., Hynan, L. S., and Weiner, M. F. (2012). Lipids and Adipokines as risk factors for Alzheimer's disease. J. Alzheimers Dis. 29, 151-157. doi: 10.3233/JAD-2012-111385

Watanabe, T., Miyazaki, A., Katagiri, T., Yamamoto, H., Idei, T., and Iguchi, T. (2005). Relationship between serum insulin-like growth factor-1 levels and Alzheimer's disease and vascular dementia. J. Am. Geriatr. Soc. 53, 1748-1753. doi: 10.1111/j.1532-5415.2005.53524.x

Wehr, H., Bednarska-Makaruk, M., Łojkowska, W., Graban, A., HoffmanZacharska, D., Kuczynska-Zardzewiały, A., et al. (2006). Differences in risk factors for dementia with neurodegenerative traits and for vascular dementia. Dement Geriatr. Cogn. Disord. 22, 1-7. doi: 10.1159/000092845

Whitmer, R. A., Sidney, S., Selby, J., Johnston, S. C., and Yaffe, K. (2005). Midlife cardiovascular risk factors and risk of dementia in late life. Neurology 64, 277-281. doi: 10.1212/01.WNL.0000149519.47454.F2

Wingo, T. S., Cutler, D. J., Wingo, A. P., Le, N. A., Rabinovici, G. D., Miller, B. L., et al. (2019). Association of early-onset Alzheimer disease with elevated lowdensity lipoprotein cholesterol levels and rare genetic coding variants of APOB. JAMA Neurol. 76, 809-817. doi: 10.1001/jamaneurol.2019.0648

Wolf, H., Hensel, A., Arendt, T., Kivipelto, M., Winblad, B., and Gertz, H. J. (2004). Serum lipids and hippocampal volume the link to Alzheimer's disease. Ann. Neurol. 56, 745-748. doi: 10.1002/ana.20289

Yamamoto, H., Watanabe, T., Miyazaki, A., Katagiri, T., Idei, T., Iguchi, T., et al. (2005). High prevalence of Chlamydia pneumoniae antibodies and increased high-sensitive C-reactive protein in patients with vascular dementia. J. Am. Geriatr. Soc. 53, 583-589. doi: 10.1111/j.1532-5415.2005.53204.x
Yamamoto, K., Kitano, Y., Shuang, E., Hatakeyama, Y., Sakamoto, Y., Honma, T., et al. (2014). Decreased lipid absorption due to reduced pancreatic lipase activity in aging male mice. Biogerontology 15, 463-473. doi: 10.1007/s10522-014-9512-5

Yavuz, B. B., Yavuz, B., Halil, M., Cankurtaran, M., Ulger, Z., Cankurtaran, E. S., et al. (2008). Serum elevated gamma glutamyltransferase levels may be a marker for oxidative stress in Alzheimer's disease. Int. Psychogeriatr. 20, 815-823. doi: 10.1017/S1041610208006790

Zhang, X., Xi, Y., Yu, H., An, Y., Wang, Y., Tao, L., et al. (2019). 27-hydroxycholesterol promotes $A \beta$ accumulation via altering A $\beta$ metabolism in mild cognitive impairment patients and APP/PS1 mice. Brain Pathol. 29, 558-573. doi: 10.1111/bpa 12698

Conflict of Interest: The authors declare that the research was conducted in the absence of any commercial or financial relationships that could be construed as a potential conflict of interest.

Copyright (c) 2020 Zhou, Liang, Zhang, Xu, Lin, Zhang, Kang, Liu, Zhao and Zhao. This is an open-access article distributed under the terms of the Creative Commons Attribution License (CC BY). The use, distribution or reproduction in other forums is permitted, provided the original author(s) and the copyright owner(s) are credited and that the original publication in this journal is cited, in accordance with accepted academic practice. No use, distribution or reproduction is permitted which does not comply with these terms. 